\title{
Energy Management of Community Microgrids Considering Degradation Cost of Battery
}

\author{
Md Alamgir Hossain ${ }^{1,2, *}$, Hemanshu Roy Pota ${ }^{1}$, Stefano Squartini ${ }^{3}$, Forhad Zaman ${ }^{1}$, Kashem M. Muttaqi ${ }^{4}$ \\ ${ }^{1}$ School of Engineering $\&$ Information Technology, The University of New South Wales, Canberra, ACT 2610, Australia \\ ${ }^{2}$ Department of Electrical \& Electronic Engineering, Dhaka University of Engineering and Technology, Gazipur, Bangladesh \\ ${ }^{3}$ Department of Information Engineering, Università Politecnica delle Marche, Ancona, Italy \\ ${ }^{4}$ School of Electrical, Computer and Telecommunications Engineering, University of Wollongong, NSW 2522, Australia
}

\begin{abstract}
A storage system is a key component of a microgrid. Over the last few years, research has been undertaken to determine optimal management of microgrid resources. Battery storage has a significant impact on the total operational cost as the lifetime of the battery reduces during charging and discharging cycles. In this paper, we propose optimal energy management of a community microgrid in which the cost function includes the degradation cost of the battery and a dynamic penalty to reflect the true operational cost. A particle swarm optimisation (PSO) is used to determine the battery control actions for real-time energy management. Several case studies are presented to demonstrate the effectiveness of the proposed framework in which the new cost function reduces electricity cost up to 44.50 per cent compared to a baseline method and 37.16 per cent compared to another existing approach.
\end{abstract}

Keywords: Community microgrids, renewable energy, optimum battery control, real-time energy management, and particle swarm optimisation.

\section{Nomenclature}

PSO Particle swarm optimisation

RESs Renewable energy sources

ESS Energy storage system

SOC State of charge

ADP Adaptive dynamic programming

I-DEMS Intelligent dynamic energy management system

PV Photovoltaic

PCC Point of common-coupling

EMU Energy management unit

$B L_{o} \quad$ Initial battery energy level

$B L_{\max } \quad$ Maximum battery energy level
$B L_{\text {min }} \quad$ Minimum battery energy level

$P_{w T} \quad$ Total wind power

$P_{s T} \quad$ Total solar power

$P_{g} \quad$ Import/export grid power

$C(t) \quad$ Grid electricity prices

$L(t) \quad$ Load at time $t$

$f_{p p d}(t) \quad$ Objective function proposed

$f_{\text {ext }}(t) \quad$ Objective function existed

$f_{p c}(C)$ Penalty cost function

RTP Real-time electricity price

WT Wind turbine

\footnotetext{
* Corresponding author

Email address: Md.Hossain6@student.adfa.edu.au or alamgir_duet@hotmail.com (Md Alamgir Hossain $\left.{ }^{1,2, *}\right)$
} 


$\begin{array}{llll}\text { SI } & \text { Solar irradiation } & \text { BS } & \text { Battery size } \\ P_{c, \text { max }} & \text { Maximum charging rate } & \text { MC } & \text { Maintenance cost } \\ P_{d, \text { max }} & \text { Maximum discharging rate } & \mathrm{CRF} & \text { Capital recovery factor } \\ \mathrm{RE} & \text { Renewable energy } & \eta & \text { Efficiency } \\ u & \text { Battery command signals } & C F & \text { Constriction factor } \\ \text { BIMC } & \text { Battery installation and maintenance cost } & \phi & \text { Constriction co-efficient } \\ \text { BC } & \text { Battery purchasing cost } & N C_{f} & \text { Numbers of cycles to failure } \\ \text { DOD } & \text { Depth of discharge } & r & \text { The annual real interest rate } \\ \alpha_{c y c} & \text { Battery degradation cost for cycles } & n & \text { Lifetime of a battery } \\ B L_{t p b} & \text { Lifetime throughput of a battery } & v & \text { Wind velocity }\end{array}$

\section{Introduction}

Over the last decade, an energy transition from fossil fuels to renewable energy sources (RESs) has significantly increased due to increasing electricity costs and rising greenhouse gas emissions [1, 2]. In 2017, the renewable energy capacity reached $2180 \mathrm{GW}$ of which solar capacity was $390 \mathrm{GW}$ and wind capacity $500 \mathrm{GW}$ [3. The high penetration of RESs into distribution networks poses technical challenges in the existing power system due to bidirectional power flow over distribution lines caused by intermittent power generation from RESs. The challenges can be minimised by breaking the centralised control of distribution networks into distributed control of certain areas called microgrids [4]. The microgrids are generally operated in a grid-tied mode in order to maximise profits and have a reliable power supply, but they can also be operated in an islanded mode to improve the supply continuity in case of grid disruptions [5]. Microgrids have a significant role in transforming the fossil-based power system to RESs-based power system.

Efficient energy management in a microgrid becomes difficult due to a number of reasons, such as, intermittent power generation by RESs, unpredictable power demand and variable real-time electricity prices [6]. These complexities increase with the decrease in the size of a microgrid in terms of power generation and demand handled. The reason is that the small size increases uncertainty levels in power management due to high unpredictable power generation and demand. This difficulty can be overcome by installing an energy storage system (ESS), such as a battery, that has the ability to store and supply energy for an economical operation of the microgrid [7].

To efficiently and effectively use the battery energy for decreasing electricity costs in a microgrid, a proper 25 formulation of the cost problem which can be solved with an efficient algorithm is crucial. Although rule-based (if-then-else) policies, with predefined sets of rules for various scenarios, are traditionally applied to control the battery energy, these policies may not always obtain an optimal solution [8, 9]. In most of these methods, within the limits of the battery constraints, the battery discharges if power generation is less than power demand and it charges if power generation is higher than power demand [10]. Consequently, frequent change in power generation and demand can cause abrupt charging/discharging decisions, decreasing the lifetime of the battery without providing actual benefits. Therefore, it is essential to include the cost of charging/discharging in the objective function to minimise operational cost in addition to the application of optimisation algorithms.

Several optimisation algorithms, such as linear programming [11, 12, evolutionary algorithm [13], dynamic 
programming [14, fuzzy logic [15] and adaptive dynamic control [16, are applied in the literature to determine 35 optimal control approaches for battery energy. An optimal power management strategy for photovoltaic (PV) generators with storage is presented in [17. The study considers battery ageing in the optimisation process and shaves peak loads to allow high integration of PV power into a distribution network using dynamic programming. In [18, a control strategy with different optimisation schemes for PV-battery systems is developed based on a day-ahead scheduling approach. Several charging goals formulated as objective functions are solved using dynamic programming. Action dependent hierarchical dynamic programming (ADHDP) for an office building is employed in [19] in which several optimisation techniques, according to the electricity consumption patterns of the rooms, are presented in order to efficiently manage energy consumption. An energy management scheme considering state of charge (SOC) and grid voltage to reduce operational costs of various energy storage systems using a sequential quadratic programming technique is presented in [20]. In [8], an intelligent dynamic energy management system (I-DEMS) used for RESs and an energy storage system to maintain continuous electricity supply of critical loads is developed.

Most of the existing literature focuses on the application of new algorithms with various objectives to decrease simulation time and determine minimum operational costs. Little attention has been paid in formulating objective functions which have a significant influence on altering the outcome of energy management algorithms. If the degradation cost for charging/discharging cycles is not considered in formulating a problem for a real-time energy management, then the operational costs of energy management increase due to the impact of the battery lifetime [21] and thereby true electricity costs are not reflected in the outcome. This paper proposes a new formulation for energy management that takes into account the degradation cost of charging/discharging cycles while minimising electricity costs for a community microgrid. To obtain solutions quickly for application in real-time operation, which can be accurately predicted than the scheduling problem, a particle swarm optimisation (PSO) is used that has faster performance and an easier implementation than other algorithms. A structurally changed PSO algorithm has been used to solve the problem proposed in this paper.

The major contributions of this study are summarised as follows.

- This paper develops a new formulation that takes into account the degradation cost of the cycle ageing in a real-time battery energy management in order to reflect the true operational cost of a microgrid.

- A dynamic penalty function to charge the battery during the hours of low price electricity is incorporated to the cost function.

- A modified PSO, which uses a different evaluation process from the conventional one for evaluating the cost function, is designed to find the optimal battery energy management in a real-time operation.

- Mathematical models for solar generators, wind generators, batteries, converters and the grid utility are presented to facilitate the analysis.

The rest of the paper is organised as follows. Section 2 introduces an overview of a community microgrid. In Section 3 . models of the various components of the community microgrid are given to facilitate the analysis. Section 4 proposes a cost function to include optimal charging hours and the degradation cost of the battery due to cycle ageing with constraints. Section 5 describes the PSO algorithm to solve the optimisation problem. Simulation results are presented in Section 6 . Section 7 presents concluding remarks from the study. 


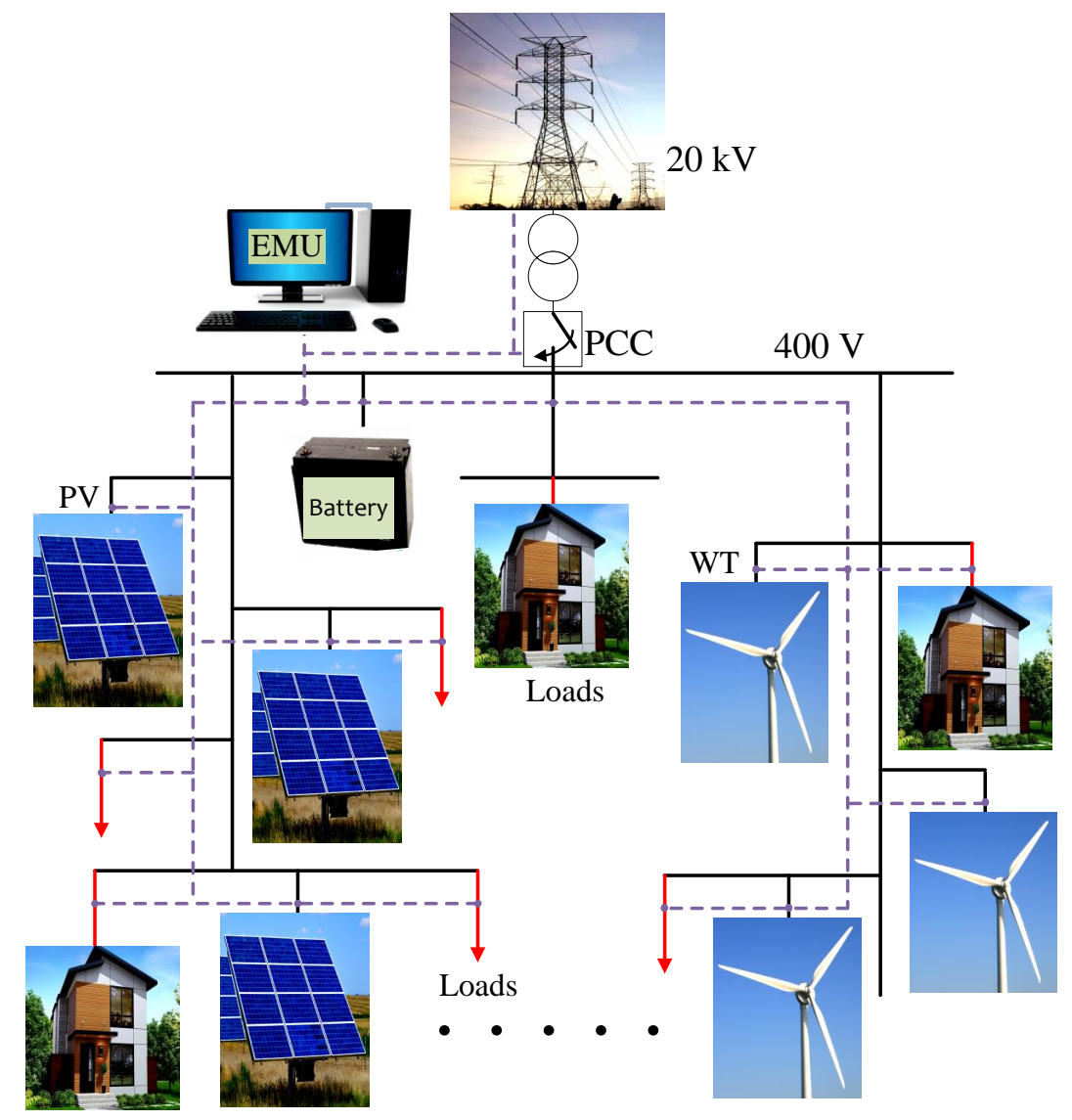

Figure 1: A community microgrid.

\section{A community microgrid}

In this study, a community microgrid is considered for which a new cost function is designed to efficiently control the battery storage system. We assume that this community with twenty houses is located in a remote area with available natural resources. Although the microgrid is connected with a grid utility but the distribution system has a limited capacity to supply power to the microgrid. To meet the power demand (maximum $36 \mathrm{kWh}$ ) of the locality, ten solar panels and five wind turbines are installed and their capacities are given in Table 2. The microgrid connected to the main grid through the point of common coupling (PCC) and a transformer is capable of operating in either islanded or grid-tied mode [22, but only the latter is considered in this study. An EMU is used in the microgrid to manage inflow and outflow powers, as shown in Figure 1. to ensure load-generation balance in the network. The EMU takes the input data of solar and wind power generation, the state of battery energy level, load profiles and real-time electricity prices (RTP) to generate reference commands for the battery energy and grid power exchange. The surplus power after fulfilling power demand is sold to the grid regardless of the electricity prices. The main purpose of the microgrid is to satisfy the power demand of the householders and reduce electricity costs using a battery system while maintaining the power supply security. The control of the battery power is the only option to reduce electricity costs as power generated by renewable sources is fully utilised to maximise profit.

The battery can be charged from both the grid utility and RESs, and it should be operated in such a way that revenues can cover at least the true operational cost as there is a degradation cost for each cycle 
representing a significant portion of the operational cost. Generally, the battery charges from the grid during the hours of the low price electricity and it charges from RESs whenever possible, leading to less profit owing to a reduced lifetime of the battery. Thus, the battery should charge/discharge when the operational benefits overcome its degradation costs. The degradation cost depends not only on the charging/discharging cycles but also other parameters, such as cycle depth, current rate, overcharge and undercharge [23, 24]. In this study, the degradation cost for cycles is only considered as other parameters can be easily controlled by enforcing the upper and lower limits of the battery energy.

The battery has three modes of operation: charging, discharging and idle. The stages are briefly described as follows.

- Charge modes: the battery can be charged from the grid and available renewable power with a limit on the charging rate to avoid battery degradation;

- Discharge modes: the battery releases energy to loads whenever RESs cannot meet the required power demand and electricity prices are high. The energy quantity must be within the battery discharging rate to protect premature degradation;

- Inactive modes: the battery has no activity (charging/discharging) in this mode because it is fully charged or discharged within the prescribed limits and the grid utility directly supplies power to loads in certain hours for maximising profit. 
Table 1: Input parameters.

\begin{tabular}{|c|c|c|}
\hline Parameter & Value & Unit \\
\hline \multicolumn{3}{|l|}{ PV generators } \\
\hline Covered area, A & 20 & $\mathrm{~m}^{2}$ \\
\hline Efficiency, $\eta_{s}$ & 18 & $\%$ \\
\hline Maximum power & 4 & $\mathrm{~kW}$ \\
\hline No of PV panels & 10 & \\
\hline \multicolumn{3}{|l|}{ Wind generators } \\
\hline Cut-in velocity & 3 & $\mathrm{~m} / \mathrm{s}$ \\
\hline Cut-out velocity & 25 & $\mathrm{~m} / \mathrm{s}$ \\
\hline Rated speed & 10 & $\mathrm{~m} / \mathrm{s}$ \\
\hline Efficiency, $\eta_{w}$ & 95 & $\%$ \\
\hline Maximum power & 5 & $\mathrm{~kW}$ \\
\hline No of wind turbines & 5 & \\
\hline \multicolumn{3}{|l|}{ Battery } \\
\hline Energy capacity & 40 & $\mathrm{kWh}$ \\
\hline Maximum energy level, $B L_{\max }$ & 36 & $\mathrm{kWh}$ \\
\hline Minimum energy level, $B L_{\min }$ & 7.2 & $\mathrm{kWh}$ \\
\hline Initial energy level, $B L_{o}$ & 18 & $\mathrm{kWh}$ \\
\hline Maximum charging rate & 4 & $\mathrm{kWh}$ \\
\hline Maximum discharging rate & -4 & $\mathrm{kWh}$ \\
\hline Cost of battery & 680 & $\$ / \mathrm{kW} \mathrm{h}$ \\
\hline Maintenance cost & 20 & $\%$ \\
\hline Interest rate & 6 & $\%$ \\
\hline Lifetime & 10 & years \\
\hline
\end{tabular}




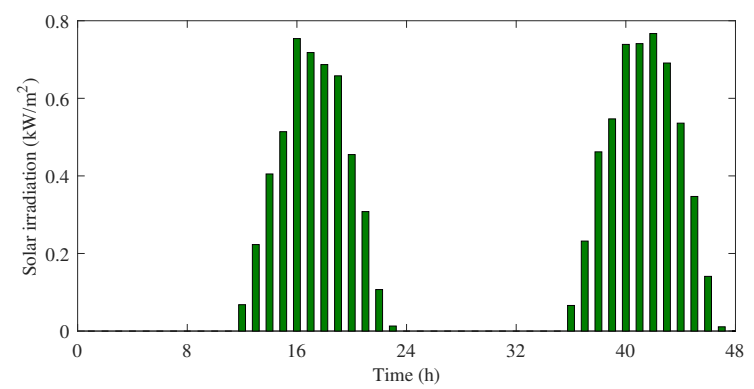

(a)

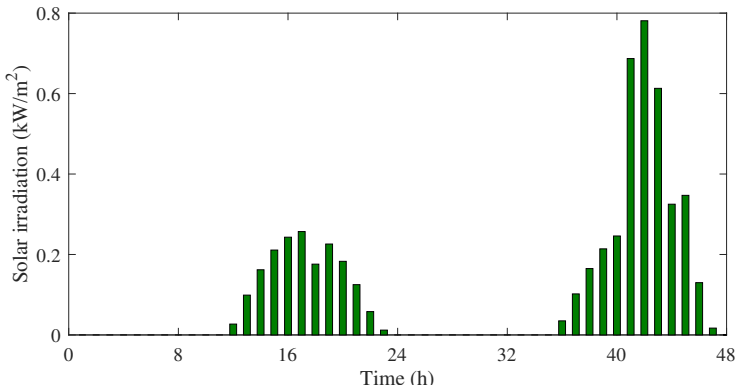

(b)

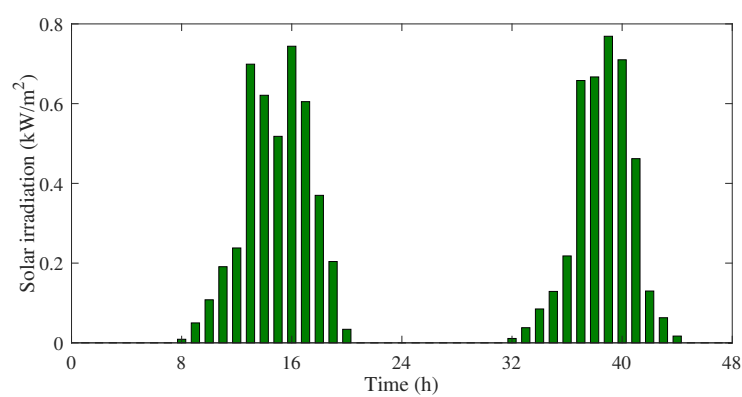

(c)

Figure 2: Solar irradiation over a 48 hour horizon: (a) Case 1 and 3, (b) Case 2 and (c) Case 4.

\section{System modeling}

\subsection{Solar generators}

Solar photovoltaic (PV) cells convert sunlight into dc electricity based on photovoltaic effect. The capacity of a PV generator is proportional to the size of PV panels and solar irradiation (SI). To exploit maximum energy produced by solar panels, they are operated in the maximum power point tracking (MPPT) mode 25]. The output power for a solar panel can be determined as follows:

$$
P_{s}=\eta_{s} \times A \times S I\left(1-0.005\left(t_{o}-25\right)\right)
$$

where $\eta_{s}$ and $A$ are the conversion efficiency (\%) and area of PV panels $\left(\mathrm{m}^{2}\right)$, respectively, and $t_{o}$ denotes outside air temperature $\left({ }^{\circ} \mathrm{C}\right)$.

The total output power for a number of solar panels can be expressed as follows:

$$
P_{s T}=P_{s} \times N_{s}
$$

where $N_{s}$ is the number of solar generators, which is ten in this study.

\subsection{Wind turbine}

The output power of a wind generator is calculated by wind speed at the hub height that has a significant influence on output power. This is because of the changing wind speed with increasing height in accordance with a power law. Wind power is proportional to the third power of the wind velocity. It is essential to convert the average hourly wind speed to corresponding values at the hub height 26. The following power law equation is commonly used to convert to hub heights.

$$
\frac{v}{v_{0}}=\left(\frac{h}{h_{0}}\right)^{\alpha}
$$




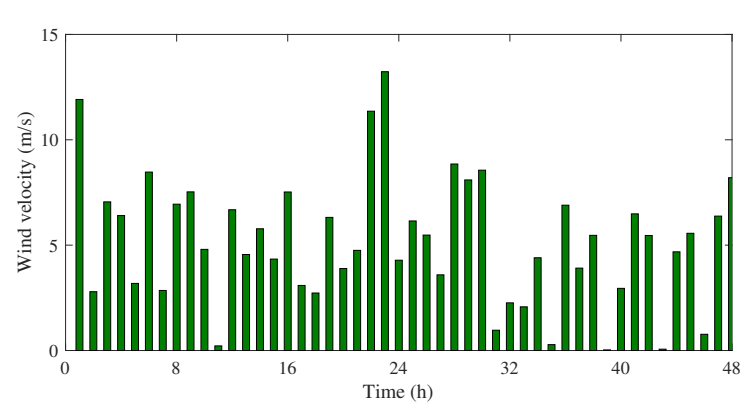

(a)

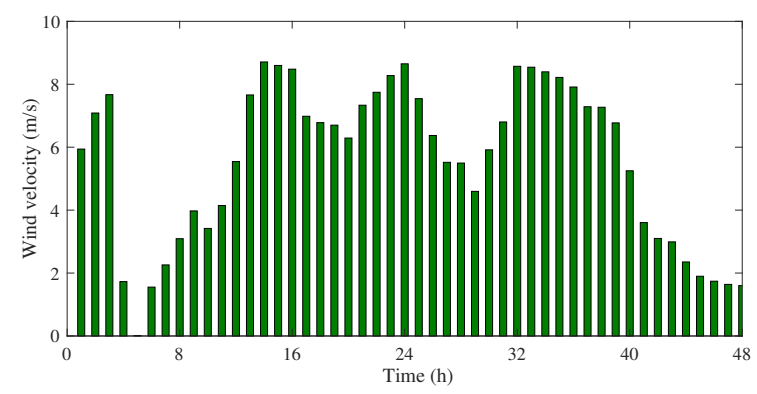

(c)

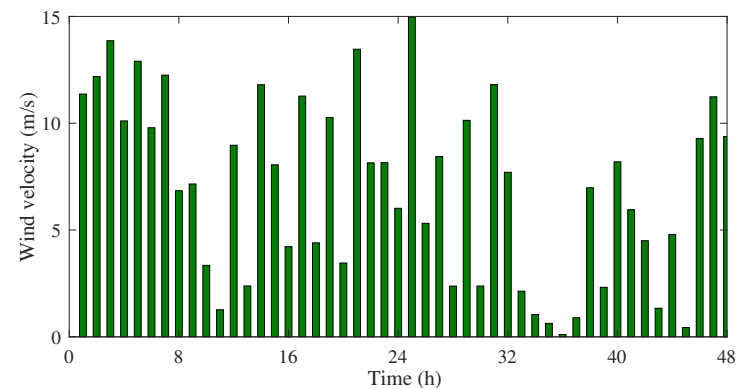

(b)

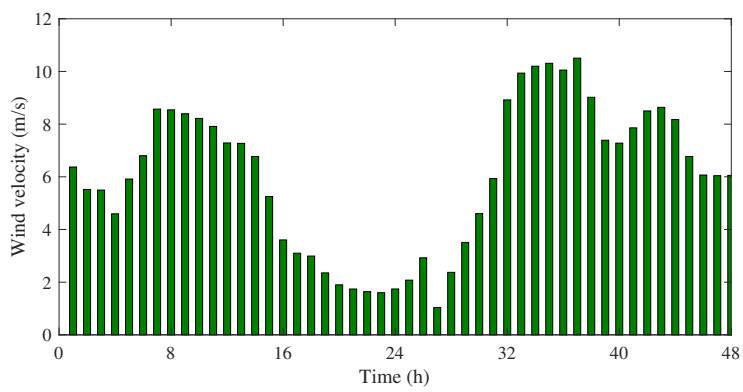

(d)

Figure 3: Wind velocity over a 48 hour time horizon: (a) Case 1, (b) Case 2, (c) Case 3 and (d) Case 4.

where $v$ is the wind speed $(\mathrm{m} / \mathrm{s})$ at desired height $(\mathrm{m}), h ; v_{0}$ the wind speed at the reference height, $h_{0} ;$ and $\alpha$ the ground surface friction coefficient. The value of $\alpha$ is generally considered as $1 / 7$ for an open space [27, 28. The wind power generated depends on wind velocities at the turbine power rating and site. The electric power of a wind turbine can be represented as a piece-wise function of the wind speed as follows [29]:

$$
P_{w}= \begin{cases}0 & \text { if } v_{f} \leq v \text { or } v \leq v_{c} \\ P_{r} \times \frac{v^{3}-v_{c}^{3}}{v_{r}^{3}-v_{c}^{3}} & \text { if } v_{c} \leq v \leq v_{r} \\ P_{r} & \text { if } v_{r} \leq v \leq v_{f}\end{cases}
$$

where $P_{r}$ is the rated electrical power; $v_{r}$ is the rated wind speed; $v$ represent wind speed; $v_{c}$ refers to cut-in wind speed; and $v_{f}$ is the cut-off wind speed.

The total output power for a number of wind turbines with the generator efficiency can be extracted as follows:

$$
P_{w T}=P_{w} \times \eta_{w} \times N_{w}
$$

where $\eta_{w}$ is the wind generator's efficiency and $N_{w}$ the number of wind generators.

\subsection{Converters}

Converters that include $\mathrm{dc} / \mathrm{dc}$ and $\mathrm{dc} / \mathrm{ac}$ conversion processes are generally used to produce the same frequency of the grid utility as the frequency of the power generated by RESs is difference. The frequency is generally matched during the conversion from dc power to ac one. As there is a power loss during the conversion process, a converter can be represented by its efficiency as follows [30, 31]:

$$
\eta_{c o n}=\frac{\frac{P_{c o}}{P_{n}}}{\frac{P_{c o}}{P_{n}}+\eta_{o}+k_{1}\left(\frac{P_{c o}}{P_{n}}\right)^{2}}
$$


where

$$
\begin{aligned}
\eta_{o} & =\left(\frac{10}{\eta_{10}}-\frac{1}{\eta_{100}}-9\right) / 99 \\
k_{1} & =\frac{1}{\eta_{100}-\eta_{o}-1}
\end{aligned}
$$

and $P_{n}$ is the nominal power; $P_{c o}$ is the output power of the converter; and $\eta_{100}$ and $\eta_{10}$ are the converter's efficiency provided by manufacturer at $100 \%$ and $10 \%$ nominal power, respectively.

\subsection{Storage systems}

The battery, one of the important elements of microgrids, is used together with the EMU to reduce electricity cost and minimise the impact of the intermittent nature of RESs. The EMU communicates with the battery system to determine its optimal operation depending on battery energy levels, power generation, electricity prices and load demand. The operational costs of the battery for charging/discharging cycles is formulated in Section 4. The behaviour of the battery can be represented as $S O C$ in $\%$ that is related to the battery energy level, $B L(t)$, at time $t$ as follows:

$$
S O C(t)=\frac{B L(t)}{B L_{\text {caps }}} \times 100
$$

subjected to

$S O C_{\min }<S O C(t)<S O C_{\max }$

where $B L_{\text {caps }}$ is the starting nominal capacity of battery; $S O C_{\min }$ and $S O C_{\max }$ are the minimum and maximum limits of the battery state of charge, respectively. The minimum limit is chosen $20 \%$ of the full SOC and the maximum limit 90\%. The limits are provided to reduce the impact on the battery ageing, i.e., prolonging the battery lifetime [20].

Alternatively, the charging/discharging cycles of the battery can also be represented with respect to battery energy levels as follows.

$$
\begin{array}{ll}
B L(t)=B L(t-1)+\Delta t P_{c}(t) \eta_{c} & \text { if the battery is charged } \\
B L(t)=B L(t-1)+\Delta t P_{d}(t) / \eta_{d} & \text { if the battery is discharged }
\end{array}
$$

subject to the following battery constraints:

Power limits:

$$
\begin{aligned}
& P_{c, \text { max }}>P_{c}(t)>0 \\
& P_{d, \max }<P_{d}(t)<0
\end{aligned}
$$

Battery energy level limits:

$$
B L_{\max }>B L(t)>B L_{\min }
$$

where $P_{c}(t)$ is the charging powers of the battery at time $t ; P_{d}(t)$ the discharging powers of the battery; $B L(t)$ the battery energy level; $\Delta t$ the interval of the time period; and $\eta_{c}$ and $\eta_{d}$ are the charging and discharging efficiency, respectively. The $\eta_{c}$ and $\eta_{d}$ are considered as unity for simplicity. 


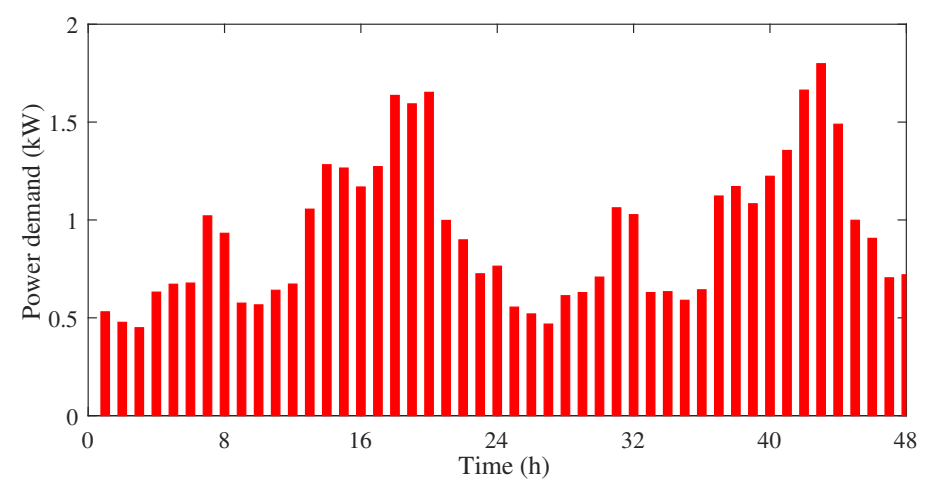

Figure 4: Power demand of a householder over a time horizon of 48 hours.

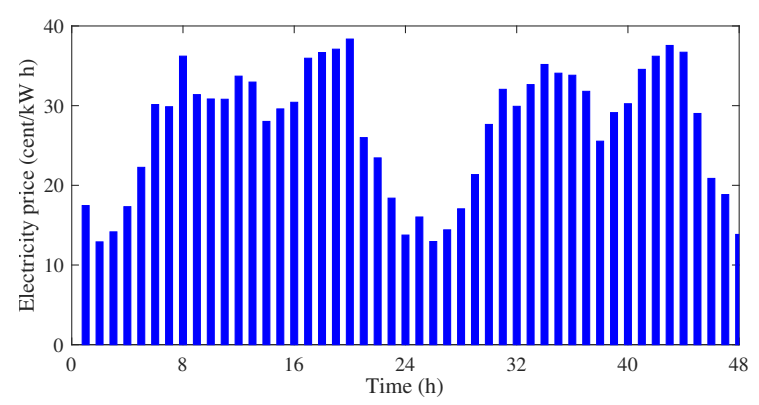

(a)

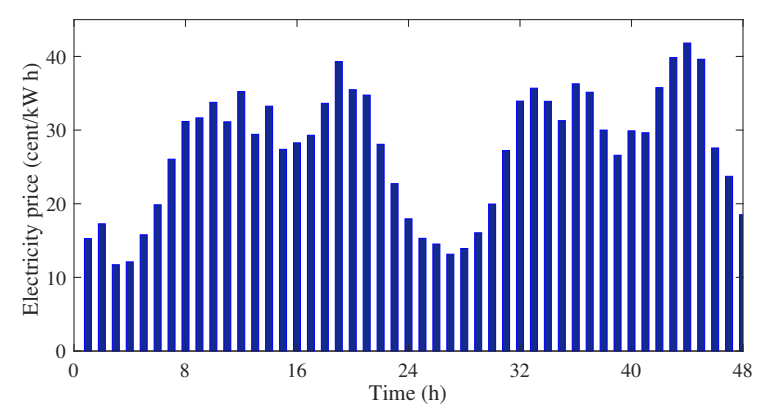

(b)

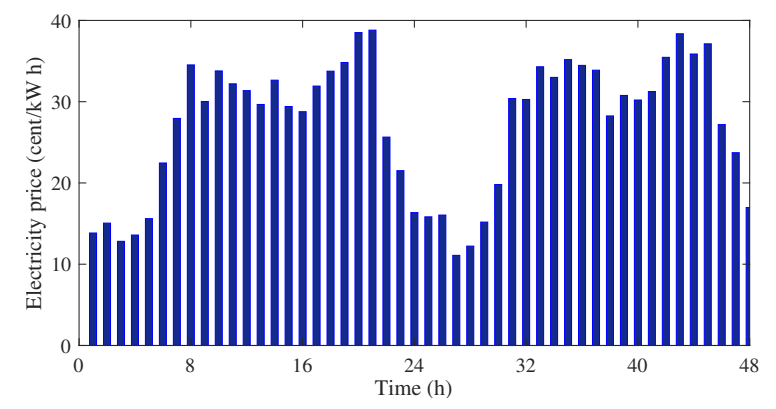

(c)

Figure 5: Real-time electricity prices for a time horizon of 48 hours: (a) Case 1 and 2, (b) Case 3 and (c) Case 4.

\subsection{Loads} over the time periods depending on wholesale electricity market is adopted due to its effectiveness over others 
34. For simplicity, the purchasing and selling RTP denoted as $C(t)$ (cents $/ \mathrm{kW} \mathrm{h}$ ) are assumed identical. The pattern of RTP taken from [35] is depicted in Figure 5. The electricity rate is suitably changed for the future electricity market of Australia.

The exchange power at time $t$ with the grid utility is marked as $P_{g}(t) \mathrm{kW}$ and it can be calculated as follows:

$$
P_{g}(t)=L(t)-P_{s T}(t)-P_{w T}(t)+u(t)
$$

with the following conditions:

- $P_{g}(t)>0$ if power is imported from the grid, and

- $P_{g}(t)<0$ if power is exported to the grid.

As distribution lines have a capacity limit, the power exchange program is limited with the following constraints:

$$
\begin{gathered}
P_{i m, \text { max }}>P_{g}>0 \\
P_{e x, \text { max }}<P_{g}<0
\end{gathered}
$$

where $P_{e x, \max }$ is the maximum power (negative value) to export to the grid utility, $P_{i m, \max }$ the maximum power to import from the grid utility through the distribution lines, and $u(t)$ the battery commands for charging/discharging energy. The line limits are imposed as $\pm 25 \mathrm{~kW}$.

\section{The proposed cost function}

The target of this study is to minimise electricity cost by controlling the battery energy optimally while reducing charging/discharging cycles. The cost function is first formulated then the PSO algorithm is applied in order to determine the optimal control operations of an ESS. The battery has three stages: charging, discharging and idle. As the charging component is a critical part for optimal battery controls due to charging the battery during the hours of the low price electricity, a dynamic penalty function is proposed in the charging component of the cost function to complete the task in an optimal way as follows:

$$
\zeta_{1}(t)=f_{p c}(C) \times\left\{B L_{\max }-(B L+u(t))\right\}
$$

where $B L_{\max }$ is the maximum battery energy levels allowed; $u(t)$ the command for battery energy and $f_{p c}(C)=$ $k-C(t)$ refers to a penalty function for charging the battery that depends on prices of the grid electricity. As changing the value of $k$, whose minimum value must equal to the maximum electricity price predicted to avoid any negative penalty, has a direct effect in reducing the electricity bills, it needs to be accurately determined to optimally charge the battery. The value of $k$ can be easily calculated using a day-ahead predicted input data of the optimisation algorithm.

Discharging a battery related to power supply for loads at time $t$ can be represented, with the inclusion of the RTP as follows:

$$
\zeta_{2}(t)=C(t) \times\left\{L(t)-\left(P_{s T}(t)+P_{w T}(t)-u(t)\right)\right\} .
$$

Equation $(12)$ is devoted to meet the power demand of the community from the battery energy to minimise electricity costs that indicate discharging the battery energy during the hours of high price electricity.

The idle state of a battery energy represents an inactive mode to avoid its energy exchange due to either 
inefficient or economical point of view. The state is related to the degradation cost of the battery for charging/discharging cycles and efficiency. For the idle state, the equation can be represented as follows [36]:

$$
\zeta_{3}(t)=\alpha_{c y c} \times(u(t)-u(t-1))
$$

where $\alpha_{c y c}$ is a battery degradation cost for cycles. The degradation cost avoids unnecessary cycles of a battery that may slightly change the electricity bill. It can be represented as follows:

$$
\alpha_{c y c}=\frac{B I M C}{B L_{t p b}}
$$

where $B I M C$ represents the installation and maintenance costs for the battery over its lifetime and $B L_{t p b}$ is the total amount of deliverable energy throughout its lifetime, called lifetime throughput. There is a linear relationship between the full equivalent discharging cycles and the capacity loss [37, 21]. The installation costs also include the purchase of the batteries, $B C$, which increase with respect to the battery size, $B S(\$ / \mathrm{kWh})$. Maintenance costs, $M C(\$ / \mathrm{kWh})$, are also proportional to the battery size. Therefore, the cost of the battery can be represented as follows.

$$
B I M C=B S \times M C+B S \times B C \times C R F
$$

where $C R F$, a ratio for determining the present value of the battery with respect to the annual real interest rate, $r$, and the lifetime, $n$, can be expressed as follows:

$$
C R F=\frac{r(1+r)^{n}}{(1+r)^{n}-1} .
$$

Depending on losses, the lifetime throughput with a depth of discharge $(D O D)$ can be calculated as follows:

$$
B L_{t p b}=\frac{B L_{c a p s}+B L_{c a p f}}{2} \times D O D \times N C_{f}
$$

where

$$
D O D(t)=\frac{B L_{c a p s}-B L(t)}{B L_{c a p s}}
$$

and $B L_{\text {caps }}$ and $B L_{\text {capf }}$ denote the starting nominal capacity and ending life capacity of the battery, respectively, and $N C_{f}$ represents the numbers of cycles to failure. By adding the charging, discharging and degradation costs together, the objective function can be formulated as follows:

$$
\begin{array}{lll}
f_{p p d}(t)=\sum_{t} \sqrt{w_{1} \zeta_{1}(t)^{2}+w_{2} \zeta_{2}(t)^{2}+w_{3} \zeta_{3}(t)^{2}} & \text { if } & L(t)>P_{s T}(t)+P_{w T} \\
f_{p p d}(t)=\sum_{t} \sqrt{w_{1} \zeta_{1}(t)^{2}+w_{3} \zeta_{3}(t)^{2}} & \text { if } & P_{s T}(t)+P_{w T}>L(t)
\end{array}
$$

where $w_{1}, w_{2}$ and $w_{3}$ are the weights of the charging, discharging and degradation components, respectively. Four different scenarios based on the availability of renewable power are analysed. If power generation is higher than power demand, the extra power either needs to be stored using the battery or sold to the grid utility depending on economical decisions set by owners to earn a profit as frequent charging/discharging cycles reduce the battery lifespan and energy efficiency. Therefore, the discharging term from the objective function is omitted when renewable power is higher than power demand to facilitate decision procedure for an optimisation algorithm to obtain optimal decisions. The minimum values of the $f_{p p d}(t)$ indicate discharging 
the battery energy during the hours of the low power generation and higher electricity prices, or charging the battery when power generation is high and prices are low. Command signals, $u$, must satisfy the battery constraints to protect the premature degradation of the battery capacity, otherwise, the command is invalid and must be discarded with a high penalty cost during an optimisation process. To improve the prediction accuracy of the power generation and demand, the cost function is evaluated for a 2 hour forecast rolling horizon as forecast errors increase with the extension of time horizons. This short-term scheduling assists to keep the battery energy at an appropriate level, where hour-by-hour operation of the battery energy may fail to do so. The algorithm runs the simulation every hour with an updated forecast over the 48 hours of operational horizon.

\subsection{Constraints:}

The following constraints to determine the feasible solutions of the cost functions are imposed.

Energy balance: The energy balance constraint:

$$
P_{g}(t)+P_{s T}(t)+P_{w T}(t)=L(t)+u(t) .
$$

The $u$ is placed at the right-hand side of the equation as the positive values indicate charging similar to a load characteristic.

Battery energy: The commanded signals, $u(t)$, must satisfy the following constraints in order to extend the lifetime and efficiency of a battery.

1) The charging and discharging rates must be within the given limitations, i.e., $\left(P_{c, \max }<u(t)<P_{d, \max }\right)$.

2) The energy level of the battery must maintain upper and lower limits, i.e., $B L_{\min }<B L+u(t)<B L_{\max }$.

\section{The metaheuristic algorithm}

The PSO, a population-based stochastic optimisation method inspired by social behaviour of fish schooling or bird flocking, was originally proposed by Eberhart and Kennedy in 1995 [38. It is classified as one of the heuristic intelligent techniques and it shares many similarities with evolutionary algorithms, such as genetic algorithms (GAs), and is successfully applied to solve numerous problems of the power system [39, 40, 13. As PSO has no evolutionary operators, for example, mutation and crossover, it is easy to implement and faster in the process than GAs. In [41, an overview of PSO in power system application is discussed with its fast convergence speed and benefits over other optimisation techniques. Due to the fast convergence rate and accuracy in the optimisation process, it is suitable for real-time application.

The PSO finds the best solution by taking iteratively improving the candidate solution. A random number of particles in the search space of the problems are generated and assessed depending on the cost function at its current location. Then each particle alters its position by measuring movements through the search space based on its own current locations, previous velocities, and overall the best locations, with some random perturbations. A velocity of each particle is iteratively altered in order to achieve the best position. The next step again begins after updating the position of each particle. In this process, the swarm as a whole is able to explore a near optimal solution [42]. Due to interaction among particles, they progress toward the optimal solution. 
The most important aspect of the PSO is its straightforward calculation method that considers only two model equations for the position and velocity vectors in an $N$-dimensional solution space. The movement and position of each particle $i$ can be expressed as $v_{i}^{k+1}$ and $x_{i}^{k+1}$ vectors, respectively, as follows:

$$
\begin{aligned}
& v_{i}^{k+1}=w v_{i}^{k}+c_{1} r_{1}\left(p_{i}^{k}-x_{i}^{k}\right)+c_{2} r_{2}\left(p_{g}^{k}-x_{i}^{k}\right) \\
& x_{i}^{k+1}=x_{i}^{k}+v_{i}^{k+1}
\end{aligned}
$$

where $v_{i}^{k}$ refers to the $i^{\text {th }}$ particle velocity for $k^{\text {th }}$ iteration in $N$-dimension, $x_{i}^{k}$ denotes $i^{\text {th }}$ particle position for $k^{\text {th }}$ iteration, $p_{i}$ is the best position of an individual particle $i$, and $p_{g}$ the best position achieved among all particles. In addition, $r_{1}, r_{2}$ are the random numbers of the uniform distribution within the range of [0 1], and $c_{1}, c_{2}$ represent learning factors used to control the significance of the best solution. One of the parameters is population size, which is often set in the range of 20-50, and the values of $w$ and $c_{1}, c_{2}$ are considered as one and two, respectively.

To restrict the particle velocity for avoiding unacceptable velocity within few iterations, the constriction coefficients to control particle velocities are proposed in [43. The coefficient regulates the particle movements and directs them toward the convergence. The modified velocities of particles can be expressed as follows:

$$
v_{i}^{k+1}=w_{C F}^{k} v_{i}^{k}+C_{1} r_{1}\left(p_{i}^{k}-x_{i}^{k}\right)+C_{2} r_{2}\left(p_{g}^{k}-x_{i}^{k}\right)
$$

where $w_{C F}=w C F$, and $C_{1}, C_{2}$ refer to the cognitive and social components that have an influence on convergence speed and the finding of an optimal point in a search space. The $C_{1}$ and $C_{2}$ can be represented as follows:

$$
\begin{aligned}
& C_{1}=C F \phi_{1} \\
& C_{2}=C F \phi_{2}
\end{aligned}
$$

where

$$
\begin{array}{r}
C F=\frac{2}{\left|\phi-2+\sqrt{\phi^{2}-4 \phi}\right|} \\
\phi=\phi_{1}+\phi_{2} \\
\phi_{1}+\phi_{2} \geq 4
\end{array}
$$

where $C F$ and $\phi$ represent a constriction factor and co-efficient, respectively. Generally, $\phi$ is set 4.1 where $\phi_{1}=\phi_{2}$. Now, the constriction particles can help in converging the process toward optimal solutions without using the velocity limits. However, a better approach is to use limits of velocities and positions.

\subsubsection{The procedure of the PSO algorithm}

The following procedure is applied for evaluating a cost function at each hour.

Part I: Initialisation

1. Use the component values from Table 1

2. Load the data of the hourly wind speed, solar irradiation, electricity price and load profile;

3. Calculate total wind power, solar power and loads; 
4. Set the parameter of the PSO:

(a) Search space dimension $=1$;

(b) Population size $=30$;

(c) Maximum number of iteration $=50$;

(d) Constriction co-efficient, $\phi=4.1$;

(e) Damping ratio for inertia coefficient, $w_{\text {damp }}=0.99$;

(f) Inertia coefficient, $w=0.73$;

(g) Penalty factor $=10^{6}$;

1. Generate the position and velocity vectors for particles randomly ;

2. Determine available battery energy for the predicted horizon;

3. Evaluate a cost function to find fitness values for input values;

4. Internal iteration start:

(a) Run the algorithm for 15 times

(b) Update the velocities and positions for particles according to Eqs. 222) and 21, respectively, within their limits;

(c) Determine available battery energy for the predicted horizon, if the battery constraints are violated, then discard the solution with the penalty factor;

(d) Calculate the cost function for the predicted time horizon;

(e) Adjust the individual best and global best values by comparing costs measured;

(f) Update inertia weight;

(g) Repeat steps from 4 until the termination criterion, i.e. maximum number of iterations, is satisfied.

\section{Simulation results}

In this section, simulation is carried out to demonstrate the effectiveness of the proposed cost function over the existing ones. The test is performed with a grid-connected microgrid, where the EMS, taking into consideration the minimum electricity costs of the community, maintains a balance power supply and demand. As the microgrid is connected to the grid utility, the power generated by solar and wind generators are fully utilised with the help of a storage system to maximise profit. Therefore, the control of the battery energy with respect to RTP is the prime goal of this study. The parameters used in this study are shown in Table 1 . It is worth mentioning that the battery size is considered $40 \mathrm{~kW} \mathrm{~h}$ equivalent to meet the maximum power demand for $1 \mathrm{~h}$ if the power limits are neglected. We assume that the energy management of the community microgrid using this small capacity for the storage system is difficult due to its frequent charging/discharging cycles during fluctuated power generation. It is also assumed that the initial battery status is known that is the idle state 


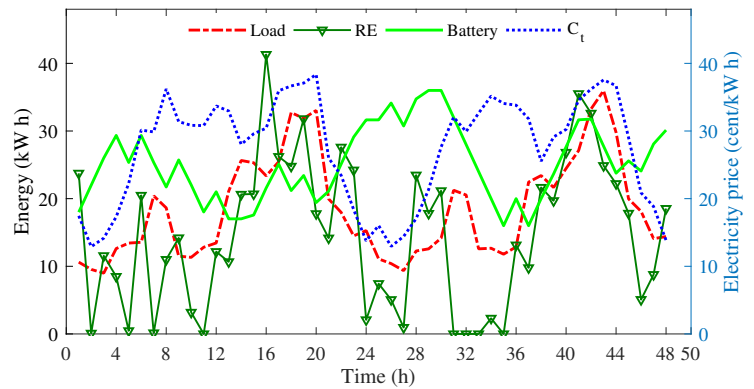

(a)

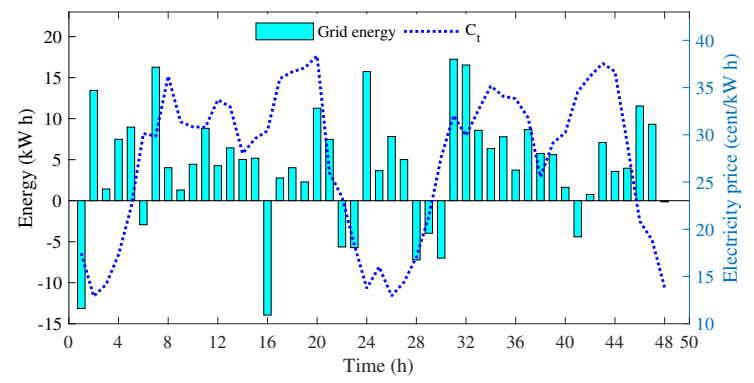

(b)

Figure 6: Existing energy management for Case 1: (a) charging/discharging cycles of the battery energy and (b) energy exchange with the grid.

\subsection{Case 1}

Existing energy management: In this simulation, the cost function presented in 32 , 44 is adopted as an existing cost function as follows:

$$
f_{\text {ext }}(t)=\sum_{t} \sqrt{\psi_{1}(t)^{2}+\psi_{2}(t)^{2}}
$$

where

$$
\begin{aligned}
& \psi_{1}(t)=\left\{L(t)-\left(P_{s T}(t)+P_{w T}-u(t)\right)\right\} \times \frac{C(t)}{C_{\text {min }}} \\
& \psi_{2}(t)=B L_{\text {max }}-(B L+u(t))
\end{aligned}
$$

and where $C_{\min }$ is the minimum RTP. In this cost function, charging and discharging components are incorporated to optimally control the battery energy, leaving behind costs associated with each cycle, i.e. idle state of a battery energy. In addition, the effects of the dynamic electricity prices on charging/discharging cycles are omitted by including minimum RTP $\left(C_{m i n}\right)$ that cannot guarantee the charging of the battery energy during the hours of the low price electricity.

The results from the charging/discharging energies and power exchanges with the grid utility for the implementation of the cost function are demonstrated in Figure 6. From Figure 6a, it is observed that the battery 


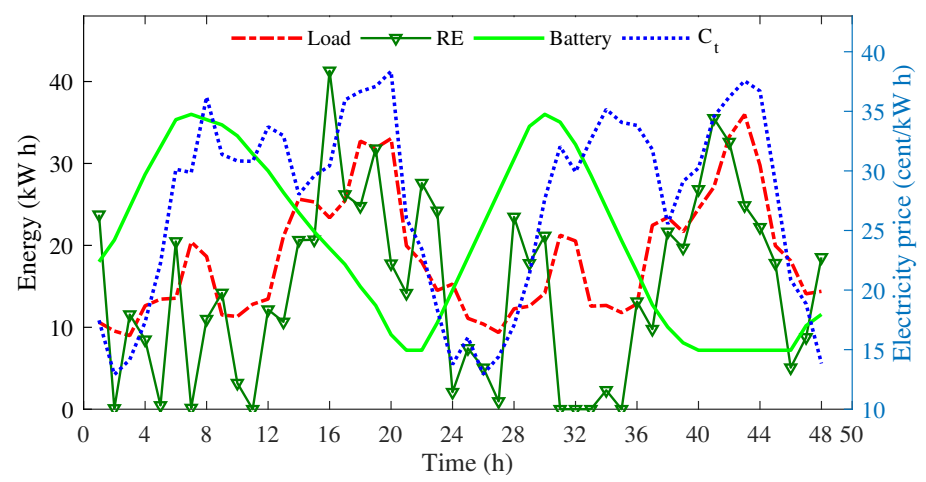

Figure 7: Proposed energy management for Case 1: optimal charging/discharging cycles of the battery energy.

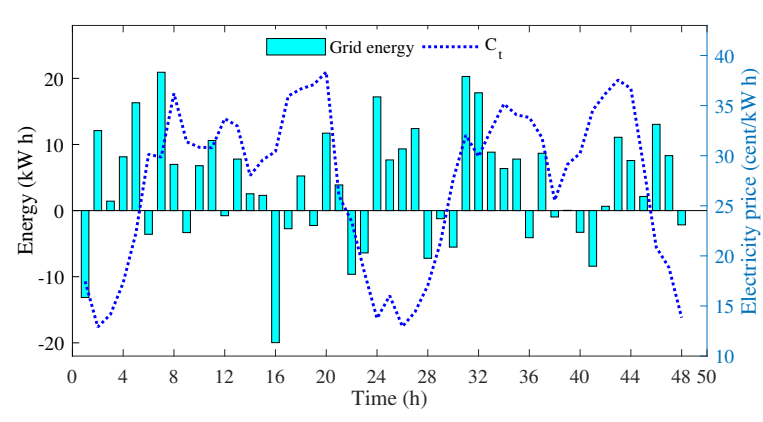

(a)

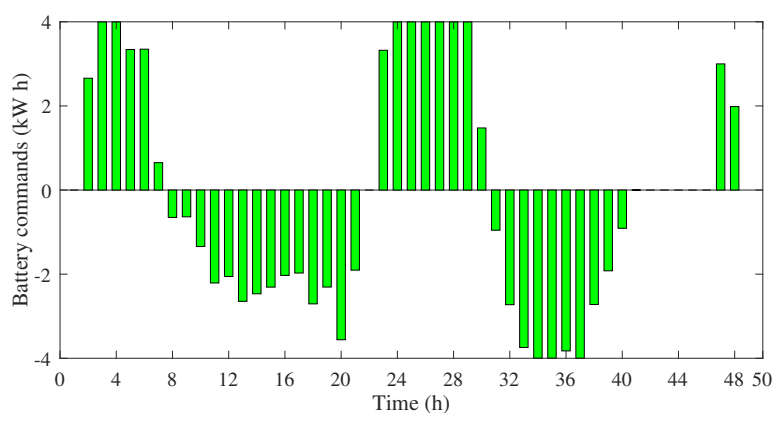

(b)

Figure 8: Proposed energy management for Case 1: (a) energy exchange with the grid utility and (b) command signals for the battery energy.

charges from the grid during the hours of the low price electricity while it charges from RESs whenever possible after fulfilling its constraints. As a result, a number of charging/discharging cycles increase, leading to a decreased lifetime of the battery due to a substantial influence on the life of the electrochemical battery cells that have limited cycle life due to the tarnishing of its material for charging/discharging cycles. Therefore, it is essential to reduce unprofitable cycles that have a fixed cost to increase the batteries' lifetime. Decreasing cycles are not an indicator to reduce profit for the installation of the battery rather it indicates that the battery can undergo charging/discharging cycles when benefits overcome the degradation costs of the battery. The electricity cost of this method is estimated as $\mathrm{A} \$ 56.60$, which is less than the cost of the baseline algorithm A $\$ 58.00$ as shown in Table 2 .

Proposed energy management: To minimise frequent cycles that have a fixed cost, this study proposes a cost function that includes cycling costs of the battery energy in order to increase overall profits. Cycling costs prevent up to a certain price of the unprofitable charging/discharging cycles and can smooth the cycles if weights are imposed in the cost function without depending on power generation from RESs. In addition, the cost function is suitably equipped with the dynamic electricity prices to charge the battery during the hours of the low price electricity. The combination of both the degradation cost and dynamic electricity prices increases the profit from the optimal battery operation. Figure 7 demonstrates the charging/discharging cycles of the battery energy for the cost function proposed. In the first 24 hours, the battery charges fully $36 \mathrm{kWh}$ at $t=7 \mathrm{~h}$ in the proposed cost function, where it charges $28.66 \mathrm{kWh}$ at $t=4 \mathrm{~h}$ in the existing function. The higher charging during the hours of the low price electricity is the result from dynamic electricity prices. It is 


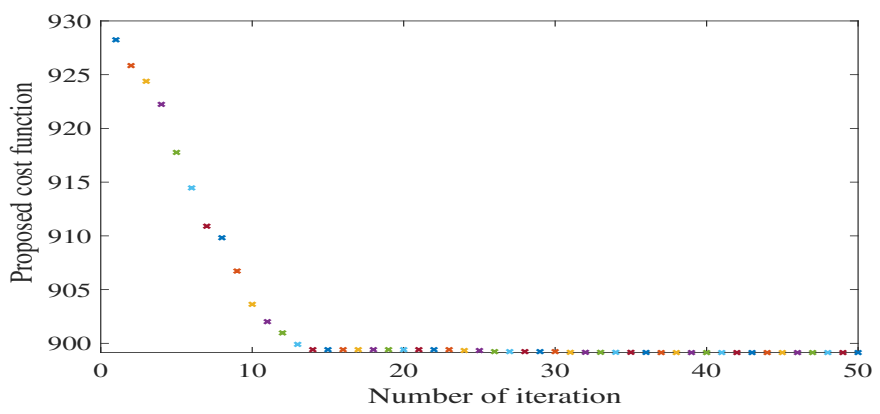

Figure 9: Convergence curve of the PSO algorithm.

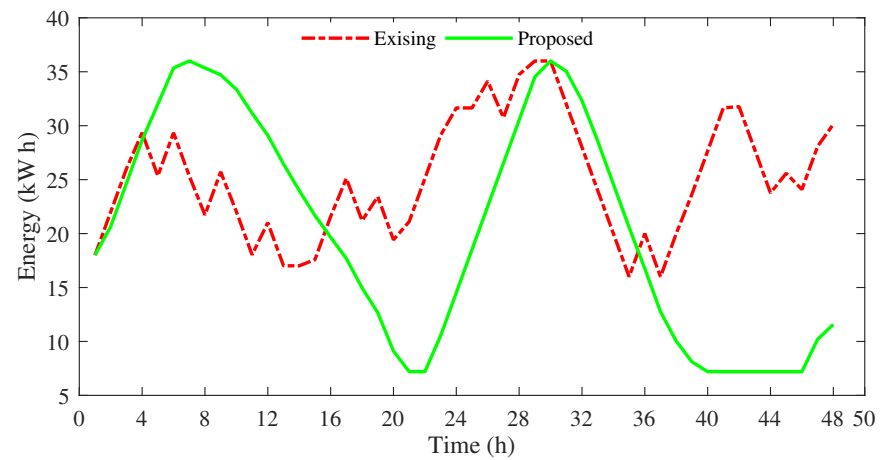

Figure 10: Comparison between the proposed and existing battery energy managements for Case 1.

observed that the number of charging/discharging cycles are dramatically reduced in the cost function proposed to decrease the electricity cost of the community. The charging/discharging commands of the battery energy and energy exchange with the grid utility are illustrated in Figure 8 . The convergence curve of the proposed method is demonstrated in Figure 9. A comparative study between the existing cost function and the proposed one is shown in Figure 10, from which it is clear that the proposed method exhibits better energy management than the existing function with reduced electricity costs and improved battery lifespan as tabulated in Table 2 The electricity cost can be saved by $16.35 \%$ and $14.31 \%$ in the proposed method as compared to the baseline approach and the existing technique, respectively. The cost saving in percentage is determined as follows:

$$
\% \text { Saving }=\frac{\text { Reference electricity cost }- \text { Measured electricity cost }}{\text { Reference electricity cost }} \times 100 \text {. }
$$

\subsection{Case 2}

Existing energy management: In this case study, different SI and wind velocities from Case 1 as shown in Figure $3 \mathrm{~b}$ and 2b, respectively, are used to clarify the effectiveness of the cost function proposed while same load profile and RTP are considered. The low SI and fluctuated wind speed may lead to frequent cycles in the existing cost function. Figure 11 shows the charging/discharging cycles of the battery energy. It is observed that frequent cycles happen in between time $t=7-31 \mathrm{~h}$. This is because of the fluctuation in renewable generation. The frequent cycles not only reduce the lifetime of a battery but also decrease efficiency of the energy transferred. At time $t=6 \mathrm{~h}$, the battery fully charges due to the higher power generation than the power demand of the community. After that, the battery is idle for $1 \mathrm{~h}$ and the extra power after satisfying constraints is exported to the grid utility. The battery discharges whenever the local power generation is less 
Table 2: Comparison between the proposed and existing energy managements for Case 1.

\begin{tabular}{|c|c|c|}
\hline Cost function & Electricity cost & $\%$ Saving \\
\hline Baseline & 58.00 & 0 \\
\hline Existing & 56.6 & 2.43 \\
\hline Proposed & 48.52 & 16.35 \\
\hline
\end{tabular}

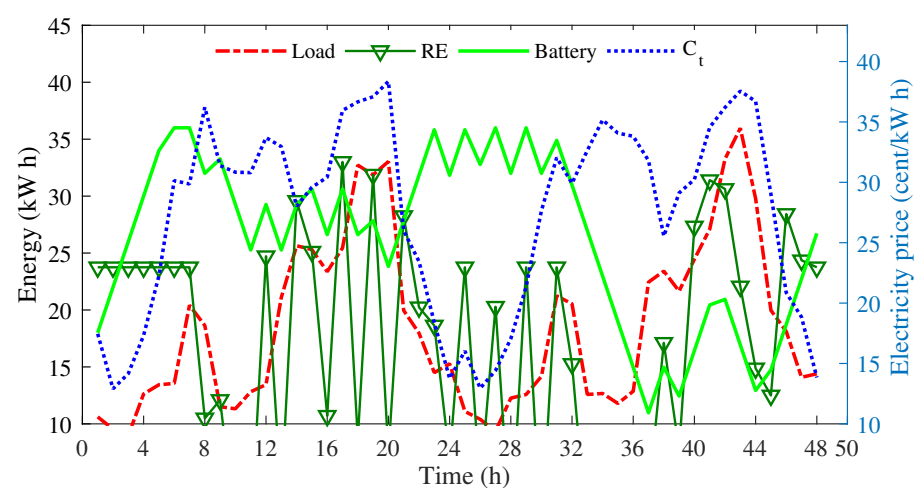

Figure 11: Existing energy management for Case 2: optimal charging/discharging cycles of the battery energy.

than the power demand noticed in Figure 11. The electricity cost for this cost function is estimated as $\mathrm{A} \$ 46.42$ that is less than the baseline algorithm, $\mathrm{A} \$ 49.70$, for 48 hours of a time horizon shown in Table 3 .

Proposed energy management: The outcome of the proposed cost function is shown in Figure 12 It is observed that the number of the charging/discharging cycles are reduced significantly although fluctuated power generation from RESs exists. The reason is that the degradation cost with incorporating a weight smooths the charging/discharging cycles regardless of the stochastic power generation from RESs to increase the profit for the application of the ESS. The energy exchange with the grid utility is demonstrated in Figure $12 \mathrm{~b}$, where the positive value indicates power imported and the negative magnitude refers to power exported. It is observed in Figure $12 \mathrm{~b}$ that power is exported up to $t=7 \mathrm{~h}$ due to the higher power generation than the power demand. A comparison between the existing cost function and the proposed one is shown in Figure 13 Electricity costs for the proposed function are calculated as $\mathrm{A} \$ 40.76$ for the 48 hours of the time horizon. The

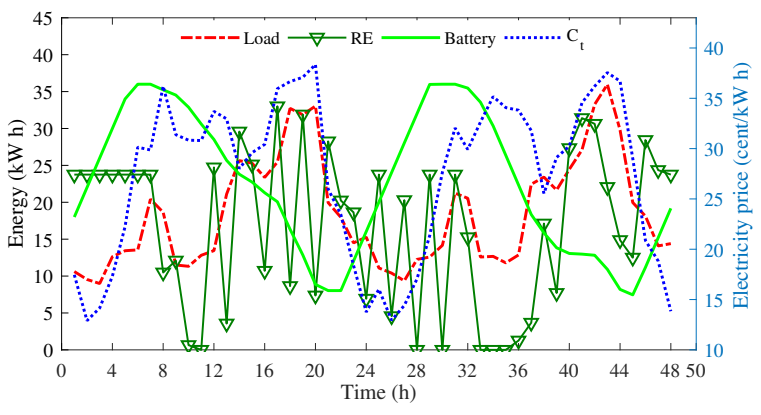

(a)

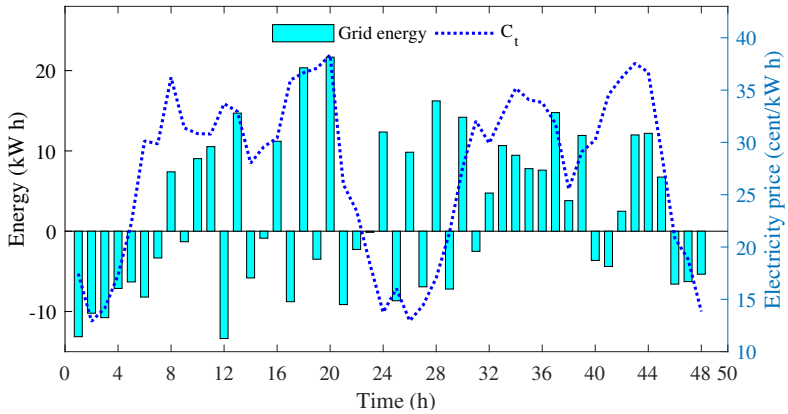

(b)

Figure 12: Proposed energy management for Case 2: (a) optimal charging/discharging cycles of the battery energy and (b) grid power exchange with the grid utility. 


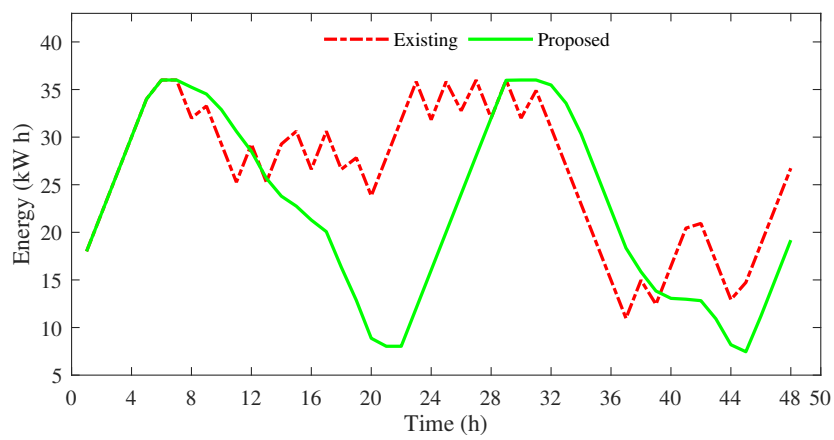

Figure 13: Comparison between the proposed and existing battery energy management for Case 2.

Table 3: Comparison between the proposed and existing energy managements for Case 2.

\begin{tabular}{|c|c|c|}
\hline Cost function & Electricity cost & $\%$ Saving \\
\hline Baseline & 49.70 & 0 \\
\hline Existing & 46.42 & 6.61 \\
\hline Proposed & 40.76 & 17.99 \\
\hline
\end{tabular}

total saving of the electricity costs shown in Table 3 is $17.99 \%$ as compared to the baseline method and 12.19 $\%$ to the existing one, which is higher in percentage reduction than Case 1. The reason for this variation is that power is exchanged with the grid utility in different time and prices. It can be concluded that frequent charging/discharging cycles and electricity costs are reduced simultaneously in the proposed cost function than the existing one.

\subsection{Case 3}

Existing energy management: This study considers a typical day power generation from solar and wind generators as shown in Figure 2a and 3c, respectively, where fluctuated power generation from wind generators is comparatively less than the power of Case 1 and 2. The power demand of the network is assumed same and the electricity price varies as shown in Figure $5 \mathrm{~b}$. It is observed from Figure 14a that the battery charges from both the grid utility and renewable energy up to $29.79 \mathrm{kWh}$ at $t=4 \mathrm{~h}$ and after that the battery discharges. The battery charges again for either rising renewable power or the higher power generation than the power

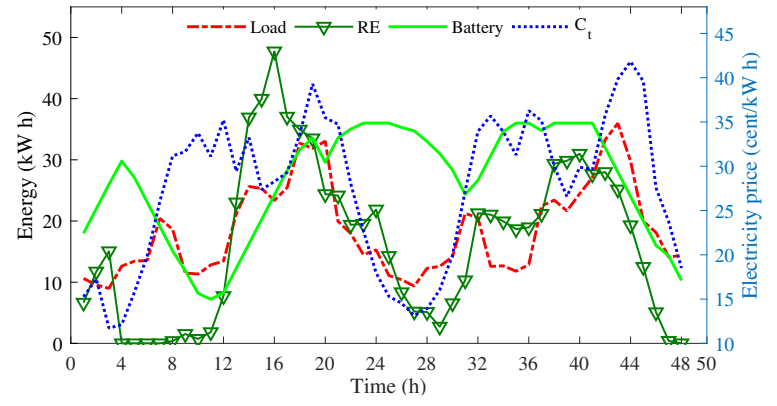

(a)

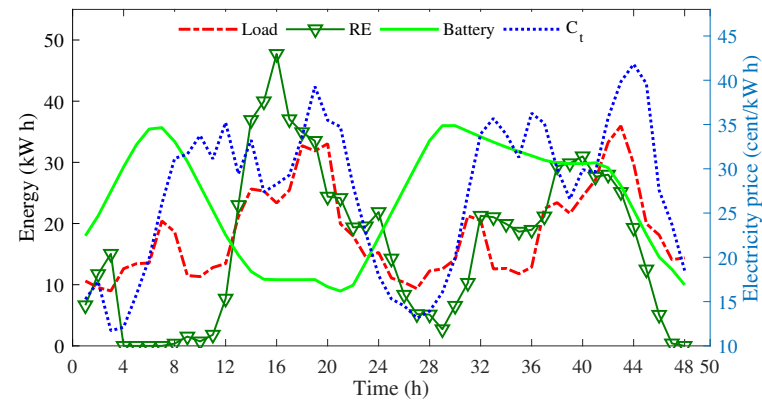

(b)

Figure 14: Optimal charging/discharging cycles of the battery energy for Case 3: (a) existing and (b) proposed energy management. 
Table 4: Comparison between the proposed and existing energy managements for Case 3.

\begin{tabular}{|c|c|c|}
\hline Cost function & Electricity cost & $\%$ Saving \\
\hline Baseline & 22.70 & 0 \\
\hline Existing & 20.05 & 11.67 \\
\hline Proposed & 12.60 & 44.50 \\
\hline
\end{tabular}

Table 5: Comparison between the proposed and existing energy managements for Case 4.

\begin{tabular}{|c|c|c|}
\hline Cost function & Electricity cost & $\%$ Saving \\
\hline Baseline & 113.96 & 0 \\
\hline Existing & 109.21 & 4.16 \\
\hline Proposed & 103.43 & 9.24 \\
\hline
\end{tabular}

demand from $t=11 \mathrm{~h}$ to $t=19 \mathrm{~h}$. The electricity cost for the community over the $48 \mathrm{~h}$ simulation is $\mathrm{A} \$ 20.50$ which is $11.67 \%$ less than the baseline cost.

Proposed energy management: The charging/discharging cycles of the battery energy for a typical day power generation are demonstrated in Figure 14b. The battery charges up to $35.67 \mathrm{~kW} \mathrm{~h}$ at $t=7 \mathrm{~h}$ from the grid utility and RESs due to the hours of the low price electricity and the higher power generation than the power demand. The battery discharges during the hours of the high price electricity although power generation from RESs is higher than the power demand. This is because of higher profit in these hours that is determined by the cost function proposed. These discharges can be controlled by inserting a conditional statement in the algorithm if owner is not willing to sell the battery energy to the grid utility. The electricity cost for this case study is $\mathrm{A} \$ 12.60$, which is $44.50 \%$ and $37.16 \%$ less than the baseline approach and the existing cost function, respectively. It is noteworthy to mention that this high amount of cost saving is because of buying power during low electricity prices from the grid and selling power during the high electricity prices from the battery as well as RESs, which are not observed in the existing cost function. In addition, higher power generation from RESs than the power demand during the hours of the high price electricity is another reason to dramatically increase the profits. A comparison between the existing energy management and the proposed one is demonstrated in Figure 15 and tabulated in Table 4

\subsection{Case 4}

Existing energy management: To verify the effectiveness of the cost function proposed, the simulation process is extended to include a day with no power generation from RESs and a day with normal power generation. The day with no power generation is added to the simulation to observe the response of the cost functions during the lack of available resources, i.e., rainy or cloudy days with wind speed less than $3 \mathrm{~m} / \mathrm{s}$ or greater than $25 \mathrm{~m} / \mathrm{s}$. Similarly, a normal day is included to demonstrate the performance of the proposed method during normal power generation scenarios with respect to the existing cost function. It is observed from Figure 16a that when there is no power in the first day, the battery charges up to $27.67 \mathrm{~kW} \mathrm{~h}$ at $t=4 \mathrm{~h}$. Afterwards, it fully discharges the energy at $t=10 \mathrm{~h}$ and remain idle until electricity price reduces to 25.64 


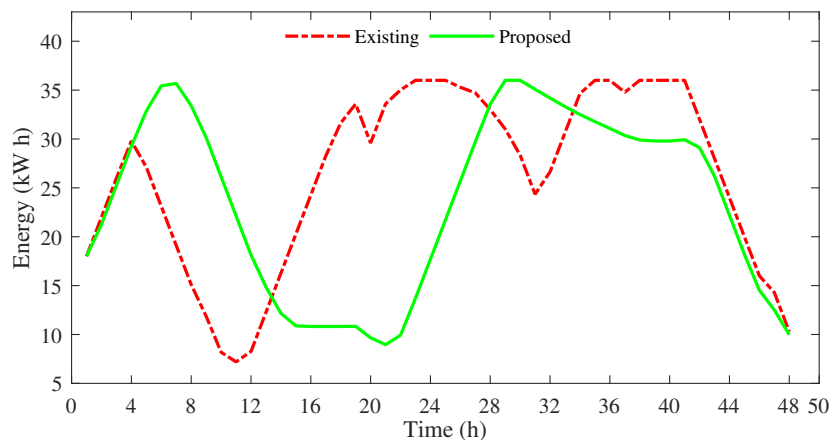

Figure 15: Comparison between the proposed and existing battery energy management for Case 3.

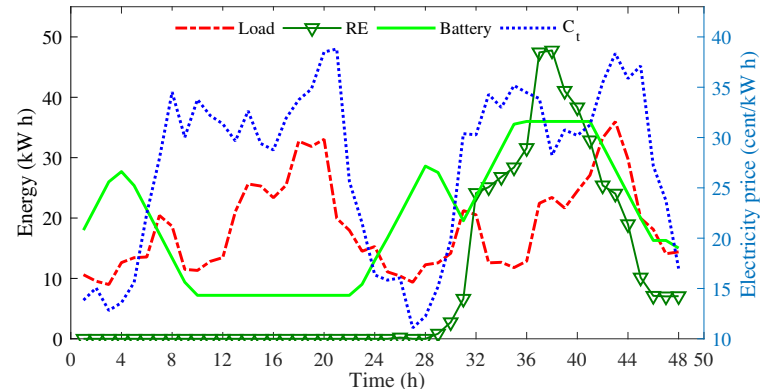

(a)

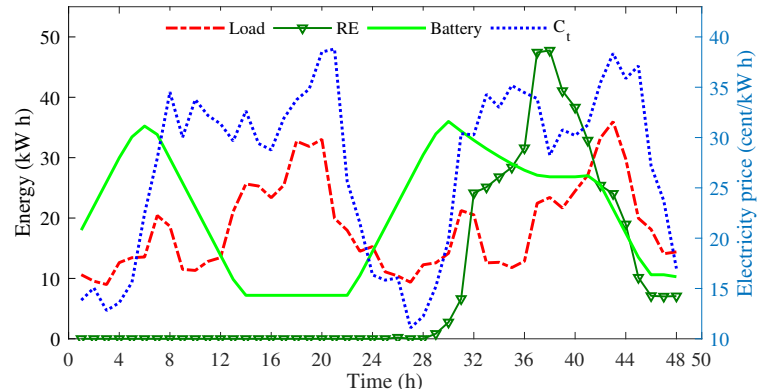

(b)

Figure 16: Optimal charging/discharging cycles of the battery energy for Case 4: (a) existing and (b) proposed energy management.

cents $/ \mathrm{kWh}$ at $t=22 \mathrm{~h}$. The battery charges again from the grid up to $28.60 \mathrm{kWh}$ at $t=28 \mathrm{~h}$ and then it discharges to meet the power demand. At $t=31 \mathrm{~h}$, the battery charges from the RESs due to higher power generation than the power demand and reaches the maximum energy levels at $t=36 \mathrm{~h}$. The battery discharges again during the low power generation than the power demand. The electricity cost of the existing cost function is $\mathrm{A} \$ 109.21$ with $4.16 \%$ reduction than the baseline approach for the two day results.

Proposed energy management: It is observed from Figure $16 \mathrm{~b}$ that the proposed energy management approach has only two cycles for the 48 hour simulation in which the battery charges from the grid utility up to $35.23 \mathrm{~kW} \mathrm{~h}$ at $t=6 \mathrm{~h}$ during the hours of the low price electricity and after that it discharges fully the energy to satisfy the power demand during the hours of the high price electricity. The battery again charges during the hours of the low price electricity and reaches the maximum energy level at $t=30 \mathrm{~h}$. It is noteworthy to mention that the battery discharges its energy from $t=30 \mathrm{~h}$ to $t=41 \mathrm{~h}$ even after renewable energy is higher than the power demand during the hours of the high price electricity due to making profits. A comparison between the proposed cost function and the existing ones is demonstrated in Figure 17 and in Table 5 . The total cost of the electricity is estimated as $\mathrm{A} \$ 103.43$ that is $9.24 \%$ less than the baseline approach for the 48 hour time horizon.

\section{Conclusion}

This paper proposes a real-time energy management in which a cost function that includes the degradation cost of the battery energy due to charge-discharge cycles and a penalty function for charging the battery from the grid utility is proposed. The battery operation based on the optimal solution of the proposed cost function 


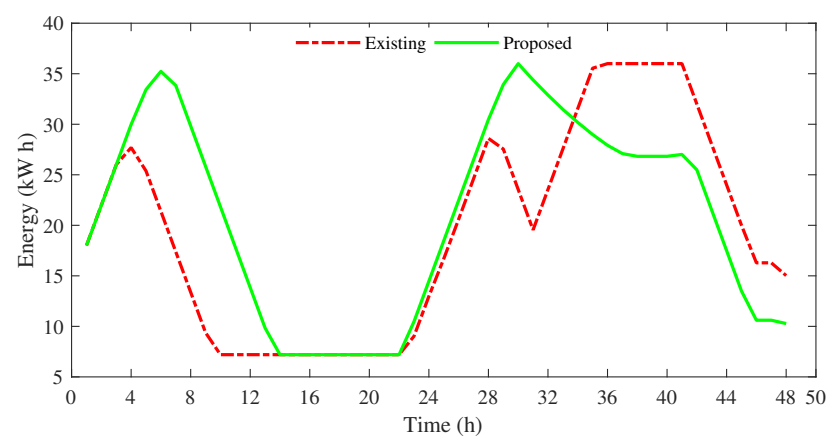

Figure 17: Comparison between the proposed and existing battery energy management for Case 4 .

reduces the electricity costs of the community microgrid while reducing unprofitable charging/discharging cycles. The PSO algorithm is used to solve the optimisation problem. It is observed that electricity costs can be reduced by $44.50 \%$ and $37.16 \%$ when the proposed cost function is used as compared to the baseline method and another existing method, respectively. Although electricity costs vary in percentage in the study due to the availability of power generation by RESs, cost reduction of the proposed energy management always outperforms the existing one with an increase in battery lifetime. The reasons for the improvement in both cost saving and battery lifespan are that two components are added to the cost function: a penalty function and cycle ageing. The effectiveness of the function proposed is justified by introducing several case studies, and it can be concluded that the performance of the cost function proposed is superior to the existing ones.

In future work, a detailed model will be considered to test the effectiveness of the proposed function from a broad perspective. In addition, demand side management of the community microgrid with the integration of electric vehicles will be included in the energy management program to effectively control the power management.

\section{Acknowledgement}

This work is supported by the Australian Government Research Training Program Scholarship at The University of New South Wales - Canberra, Australia.

\section{References}

[1] M. A. Hossain, H. R. Pota, M. J. Hossain, A. M. O. Haruni, Active power management in a low-voltage islanded microgrid, International Journal of Electrical Power \& Energy Systems 98 (2018) 36-47.

[2] M. A. Hossain, H. R. Pota, A. M. O. Haruni, M. J. Hossain, Dc-link voltage regulation of inverters to enhance microgrid stability during network contingencies, Electric Power Systems Research 147 (2017) $233-244$.

[3] A. Whiteman, T. Rinke, J. Esparrago, S. Elsayed, Renewable capacity statistics 2018, IRENA 3 (2018) 29.

[4] M. A. Hossain, H. R. Pota, W. Issa, M. J. Hossain, Overview of ac microgrid controls with inverterinterfaced generations, Energies 10 (9) (2017) 1300. 
[5] D. Wang, J. Qiu, L. Reedman, K. Meng, L. L. Lai, Two-stage energy management for networked microgrids with high renewable penetration, Applied Energy 226 (2018) 39-48.

[6] M. A. Hossain, H. R. Pota, M. J. Hossain, F. Blaabjerg, Evolution of microgrids with converter-interfaced generations: Challenges and opportunities (2018), preprints.

[7] M. A. Hossain, H. R. Pota, S. Squartini, A. F. Abdou, Modified pso algorithm for real-time energy management in grid-connected microgrids (2018), preprints.

[8] G. K. Venayagamoorthy, R. K. Sharma, P. K. Gautam, A. Ahmadi, Dynamic energy management system for a smart microgrid, IEEE transactions on neural networks and learning systems 27 (8) (2016) 1643-1656.

[9] Q. Wei, D. Liu, F. L. Lewis, Y. Liu, J. Zhang, Mixed iterative adaptive dynamic programming for optimal battery energy control in smart residential microgrids, IEEE Transactions on Industrial Electronics 64 (5) (2017) 4110-4120.

[10] G. P. Henze, R. H. Dodier, Adaptive optimal control of a grid-independent photovoltaic system, in: ASME Solar 2002: International Solar Energy Conference, American Society of Mechanical Engineers, 2002, pp. 139-148.

[11] A. C. Luna, N. L. Diaz, F. Andrade, M. Graells, J. M. Guerrero, J. C. Vasquez, Economic power dispatch of distributed generators in a grid-connected microgrid, in: Power Electronics and ECCE Asia (ICPE-ECCE Asia), 2015 9th International Conference on, IEEE, 2015, pp. 1161-1168.

[12] A. C. L. Hernández, N. L. D. Aldana, M. Graells, J. C. V. Quintero, J. M. Guerrero, Mixed-integer-linearprogramming-based energy management system for hybrid pv-wind-battery microgrids: Modeling, design, and experimental verification, IEEE Transactions on Power Electronics 32 (4) (2017) 2769-2783.

[13] M. Zaman, S. M. Elsayed, T. Ray, R. A. Sarker, Evolutionary algorithms for dynamic economic dispatch problems, IEEE Transactions on Power Systems 31 (2) (2016) 1486-1495.

[14] Y. Choi, H. Kim, Optimal scheduling of energy storage system for self-sustainable base station operation considering battery wear-out cost, Energies 9 (6) (2016) 462.

[15] A. Chaouachi, R. M. Kamel, R. Andoulsi, K. Nagasaka, Multiobjective intelligent energy management for a microgrid, IEEE Transactions on Industrial Electronics 60 (4) (2013) 1688-1699.

[16] Q. Wei, G. Shi, R. Song, Y. Liu, Adaptive dynamic programming-based optimal control scheme for energy storage systems with solar renewable energy, IEEE Transactions on Industrial Electronics 64 (7) (2017) 5468-5478.

[17] Y. Riffonneau, S. Bacha, F. Barruel, S. Ploix, Optimal power flow management for grid connected pv systems with batteries, IEEE Transactions on Sustainable Energy 2 (3) (2011) 309-320.

[18] J. Li, M. A. Danzer, Optimal charge control strategies for stationary photovoltaic battery systems, Journal of Power Sources 258 (2014) 365-373. 
[19] G. Shi, Q. Wei, D. Liu, Optimization of electricity consumption in office buildings based on adaptive dynamic programming, Soft Computing 21 (21) (2017) 6369-6379.

[20] M. J. M. Al Essa, Management of charging cycles for grid-connected energy storage batteries, Journal of Energy Storage 18 (2018) 380-388.

[21] B. Xu, J. Zhao, T. Zheng, E. Litvinov, D. S. Kirschen, Factoring the cycle aging cost of batteries participating in electricity markets, IEEE Transactions on Power Systems 33 (2) (2018) 2248-2259.

[22] M.-H. Khooban, T. Niknam, M. Shasadeghi, T. Dragicevic, F. Blaabjerg, Load frequency control in microgrids based on a stochastic noninteger controller, IEEE Transactions on Sustainable Energy 9 (2) (2018) $853-861$.

[23] J. Vetter, P. Novak, M. R. Wagner, C. Veit, K.-C. Möller, J. Besenhard, M. Winter, M. Wohlfahrt-Mehrens, C. Vogler, A. Hammouche, Ageing mechanisms in lithium-ion batteries, Journal of power sources 147 (1-2) (2005) 269-281.

[24] C. A. Correa-Florez, A. Gerossier, A. Michiorri, G. Kariniotakis, Stochastic operation of home energy management systems including battery cycling, Applied Energy 225 (2018) 1205-1218.

[25] Y.-Y. Hong, A. A. Beltran, A. C. Paglinawan, A robust design of maximum power point tracking using taguchi method for stand-alone pv system, Applied Energy 211 (2018) 50-63.

[26] B. Ai, H. Yang, H. Shen, X. Liao, Computer-aided design of pv/wind hybrid system, Renewable energy 28 (10) (2003) 1491-1512.

[27] S. Rehman, N. M. Al-Abbadi, Wind shear coefficients and energy yield for dhahran, saudi arabia, Renewable Energy 32 (5) (2007) 738-749.

[28] R. Farrugia, The wind shear exponent in a mediterranean island climate, Renewable Energy 28 (4) (2003) 647-653.

[29] B. S. Borowy, Z. M. Salameh, Optimum photovoltaic array size for a hybrid wind/pv system, IEEE Transactions on energy conversion 9 (3) (1994) 482-488.

[30] C. Darras, S. Sailler, C. Thibault, M. Muselli, P. Poggi, J. Hoguet, S. Melscoet, E. Pinton, S. Grehant, F. Gailly, et al., Sizing of photovoltaic system coupled with hydrogen/oxygen storage based on the oriente model, International Journal of Hydrogen Energy 35 (8) (2010) 3322-3332.

[31] H. Borhanazad, S. Mekhilef, V. G. Ganapathy, M. Modiri-Delshad, A. Mirtaheri, Optimization of microgrid system using mopso, Renewable Energy 71 (2014) 295-306.

[32] D. Fuselli, F. De Angelis, M. Boaro, S. Squartini, Q. Wei, D. Liu, F. Piazza, Action dependent heuristic dynamic programming for home energy resource scheduling, International Journal of Electrical Power \& Energy Systems 48 (2013) 148-160.

[33] D. Liu, Y. Xu, Q. Wei, X. Liu, Residential energy scheduling for variable weather solar energy based on adaptive dynamic programming, IEEE/CAA Journal of Automatica Sinica 5 (1) (2018) 36-46. 
[34] K. Steriotis, G. Tsaousoglou, N. Efthymiopoulos, P. Makris, E. M. Varvarigos, A novel behavioral real time pricing scheme for the active energy consumers participation in emerging flexibility markets, Sustainable Energy, Grids and Networks 16 (2018) 14-27.

[35] ComEd, USA, http://www.thewattspot.com/.

[36] I. Ranaweera, O.-M. Midtgård, M. Korpås, Distributed control scheme for residential battery energy storage units coupled with pv systems, Renewable Energy 113 (2017) 1099-1110.

[37] E. Lemaire-Potteau, F. Mattera, A. Delaille, P. Malbranche, Assessment of storage ageing in different types of pv systems: technical and economical aspects, in: 23rd European Photovoltaic Solar Energy Conference (Valencia, Spain, 2008), 2008, pp. 2765-2769.

[38] J. Kennedy, R. Eberhart, C. 1995. particle swarm optimization, in: IEEE International Conference on Neural Networks (Perth, Australia), IEEE Service Center, Piscataway, NJ, pp. 1942-1948.

[39] V. S. Pappala, I. Erlich, Power system optimization under uncertainties: A pso approach, in: Swarm Intelligence Symposium, 2008. SIS 2008. IEEE, IEEE, 2008, pp. 1-8.

[40] M. AlRashidi, M. AlHajri, A. Al-Othman, K. El-Naggar, Particle swarm optimization and its applications in power systems, in: Computational Intelligence in Power Engineering, Springer, 2010, pp. 295-324.

[41] Y. Del Valle, G. K. Venayagamoorthy, S. Mohagheghi, R. G. Harley, J. Hernandez, Particle swarm optimization: basic concepts, variants and applications in power systems, IEEE Transactions on Evolutionary Computation 12 (2) (2008) $171-195$.

[42] R. Poli, J. Kennedy, T. Blackwell, Particle swarm optimization, Swarm intelligence 1 (1) (2007) 33-57.

[43] M. Clerc, J. Kennedy, The particle swarm-explosion, stability, and convergence in a multidimensional complex space, IEEE transactions on Evolutionary Computation 6 (1) (2002) 58-73.

[44] S. Squartini, M. Boaro, F. De Angelis, D. Fuselli, F. Piazza, Optimization algorithms for home energy resource scheduling in presence of data uncertainty, in: Intelligent Control and Information Processing (ICICIP), 2013 Fourth International Conference on, IEEE, 2013, pp. 323-328. 